\title{
Yulaf Taçlı Pası Hastalığı (Puccinia coronata f. sp. avenae)
}

\author{
Oat Crown Rust Disease (Puccinia coronata f. sp. avenae)
}

\section{Selçuk SUNULU ${ }^{1}$}

Ziya DUMLUPINAR ${ }^{*}$

Mustafa YILDIRIM ${ }^{3}$

${ }^{1}$ Kayseri İl Tarım ve Orman Müdürlüğü

(iD) 0000-0002-1806-2547

${ }^{2}$ Kaharamanmaraş Sütçü İmam Üniversitesi, Ziraat Fakültesi, Tarımsal Biyoteknoloji

Bölümü

(iD) 0000-0001-6054-8893

${ }^{3}$ Kaharamanmaraş Sütçü İmam Üniversitesi, Ziraat Fakültesi, Tarla Bitkileri Bölümü

(iD) 0000-0002-9523-4007

*Sorumlu Yazar: zdumlupinar@ksu.edu.tr

Gönderilme Tarihi : 29 Şubat 2020

Kabul Tarihi : 22 Nisan 2020

\section{ÖZET}

Kültürü yapılan yulaf (Avena sativa L. ve Avena byzantina Coch.), insan ve hayvan beslemesinde kullanılmakta ve mısır, buğday, arpa, çeltik ve darıdan sonra Dünya'da en fazla üretimi yapılan tahıldır. Yulaf taçlı pas (Puccinia coronata f. sp. avenae) hastalı̆̆ yulafin en yaygın ve ekonomik zarara yol açan hastalığıdır. Etmenin teliosporelarının uç kısımlarının mikroskop altındaki görüntüsü taç şekline benzetildiği için bu ismi almıştır. Yulaf taçlı pas hastalığı çok kurak bölgeler hariç dünyanın her yerinde yulaf (Avena spp.) yetiştirilen alanlarda epidemi yaparak \%10'dan \%40'a kadar verim kayılarına sebep olabilmekte ve hassas çeşitlerdeki şiddetli enfeksiyonlarda üründe önemli verim ve kalite kayıpları gerçekleşmektedir. Yulaf taçlı pas hastalığının kontrolünde erken ekim, sık ekimden kaçınma (uygun ekim normu kullanma), aşırı azotlu gübreleme yapılmaması, alternatif/ara konukçuların yok edilmesi, dayanıklı çeşit kullanılması ve fungisit uygulamaları önerilmektedir. Etmenin eşeyli ve eşeysiz üremeyi kapsayan yaşam döngüsünden dolayı virülenslik ve agresiflik bakımından farklı periyotlarda yeni hastalık ırklarının ortaya çıkması hastalığa karşı mevcut dayanıklılık 
kaynaklarının etkinliğini olumsuz yönde etkilemektedir. Ülkemizde "Yulaf Taçlı Pas" hastalığı ile ilgili çalışmalar sınırlı düzeydedir. $\mathrm{Bu}$ derleme ile; yulafin en önemli ve yaygın hastalığı kabul edilen yulaf taçlı pas hastalığının coğrafi dağılımı, ekonomik önemi, biyolojisi, belirtileri, zararı, konukçuları ve mücadelesi ile ilgili güncel bilgilerin verilmesi amaçlanmış ve ülkemizde bu hastalığın kontrol edilmesine ilişkin öneriler sunulmuştur.

Anahtar Kelimeler: Yulaf, Yulaf taçlı pas hastalığ 1 , Puccinia coronata f. sp. avenae

\section{ABSTRACT}

Cultivated oat (Avena sativa L. and Avena byzantina (och) is used in human and animal feed and the most produced cereal after corn, wheat, barley, rice and millet in the world. Oat crown rust (Puccinia coronata f. sp. avenae) is the most common and harmful disease of oats. It is named as crown rust due to image of the teliospores' tips under the microscope that resembles the shape of the crown. Oat crown rust (Puccinia coronata f. sp. avenae) is epidemic in oat (Avena spp.) growing areas in the world, except in arid regions, causing yield losses from $10 \%$ to $40 \%$ and may cause significant yield and quality losses in susceptible cultivars in terms of severe infections. In the control of oat crown rust (Puccinia coronata $\mathrm{f}$. sp. avenae), early sowing, avoiding high sowing rates (using the appropriate sowing norm), nonexcessive nitrogen fertilization, removing plant residues, using resistant varieties and fungicide applications are recommended. Due to the life cycle of sexual and asexual reproduction of the agent, the emergence of new crown rust races in terms of virulence and aggressiveness in different periods affects the success of the existing sources of resistance to the disease negatively. In our country, studies on oat crown rust (Puccinia coronata f. sp. avenae) are limited. With this review, it is aimed to provide information on the geographical distribution, economic importance, biology, symptoms, harm, host and control of the oat crown rust (Puccinia coronata f. sp. avenae), which is considered the most important and destructive disease of oats. Suggestions for what to do against the disease are presented.

Key words: Oats, crown rust, Puccinia coronata f. sp. avenae

\section{Giriş}

Hexaploidyulaf(Avenasativa L. ve Avena byzantina Coch. $(2 \mathrm{n}=6 \mathrm{x}=42))$, insan ve hayvan beslemesinde kullanılan, misır, buğday, arpa, çeltik ve darıdan sonra en çok üretimi yapılan tahıldır (Strychar, 2011; Dumlupınar vd., 2012; Miller vd., 2018;). Tane üretimi, örtücü bitki, yem, kuru ve yeşil ot, silaj, saman ve hayvan altlığ 1 gibi amaçlarla yetiştirilmektedir. Toplam üretimin \%74'ü hayvan beslemesinde, \%26's1 ise yulaf ezmesi, yulaf unu, yulaf kepeği, yulaf gevreği gibi kahvaltılık tahıllar ve diğer gıda ürünlerinde bileşen olarak ve bazı endüstriyel uygulamalarda kullanılmaktadır. Yulafın insan beslenmesindeki tüketimi refah seviyesi, sağlıklı beslenme bilinci ve besin içeriğine bağlı olarak son yıllarda artış göstermiştir (Strychar, 2011). Yulaf iyi bir protein, lif, mineral ve vitamin kaynağıdır. Kabuğu soyulmuş yulaf tanesi 
$\% 12-20$ protein ve $\% 3-6$ oranında beta-glukan içermektedir. Suda çözünebilir bir lif olan betaglukan kullanımı tip 2 diyabet ve koroner kalp hastalıkları riskini azaltmaktadır (Ludwig vd., 1999; Maki vd., 2007).

Yulaf, çoğunlukla serin ve nemli iklime sahip alanlarda yetiştirilmekle birlikte, en ideal yetiştirme şartları iyi drene olmuş topraklar, uzun 1lık günler ve yeterli su varlığıdır. Diğer küçük taneli tahıllarla karşılaştırıldığında yetiştiriciliği değişken toprak türlerine (kumlu tınlı topraklardan ağır killi topraklara kadar) daha iyi adapte olabilmekte ve asit karakterli topraklarda iyi performans gösterebilmektedir (Strychar, 2011; Dumlupinar vd., 2012; Lin, 2012).

Dünya yulaf üretimi 2019 yılında toplam 9.72 milyon hektar alanda 21.92 milyon ton ve ortalama tane verimi $226 \mathrm{~kg} \mathrm{da}^{-1}$ olarak gerçekleşmiştir. Yulaf üretiminde 7.72 milyon ton ile Avrupa Birliği (28 ülke) ilk sırada yer alırken, 4.72 milyon tonla Rusya ikinci, 3.44 milyon tonla Kanada üçüncü sırada yer almıştır. $\mathrm{Bu}$ ülkeleri 890 bin tonla Avustralya ve 820 bin tonla Amerika Birleşik Devletleri takip etmiştir. Ülkemizde ise 100 bin hektar alanda, 230 bin ton tane yulaf üretilmiş ve ortalama verim $230 \mathrm{~kg} \mathrm{da}^{-1}$ olarak gerçekleşmiş ve 256 bin hektar alanda da yeşil ot üretimi yapılmıştır (Anonim, 2020a). En büyük yulaf ihracatçısı ülke 1.80 milyon ton ile Kanada olurken, bunu 250 bin tonla Avustralya ve 140 bin tonla Rusya takip etmiştir. Yulaf ithalatında ise 1.70 milyon tonla Amerika Birleşik Devletleri ilk sırada yer alırken, 200 bin tonla Çin ikinci, 100 bin tonla Meksika üçüncü sırada yer almıştır (Anonim, 2020a).

Yulaf türleri (Avena spp.) kromozom sayısı ve genom yapısına göre diploid, tetraploid ve hexaploid olmak üzere üç ploidi seviyesine sahiptir. A, C ve D genomlarını taşıyan yabani ve kültüre alınmış yulaflar hexaploid olup temel kromozom sayısı diğer serin iklim tahılları gibi n=7'dir. Hexaploid Avena türlerindeki A-genomu atas1 diploid Avena canariensis, C-genomu atas1 Avena ventricosa olarak bilinmektedir. D-genomunun Diploid atası henüz rapor edilmiştir (Loskutov ve Rines, 2011; Lin, 2012). Yulaf taçlı pas hastalığına (Puccinia coronata $\mathrm{f}$. sp. avenae) karşı etkili dayanıklı genlerin çoğu Avena strigosa (AA-diploid), Avena barbata (AABB-tetraploid) ve Avena sterilis (AACCDDhexaploid)'den kültür yulaflarına aktarılmıştır (Carson, 2009; Loskutov ve Rines, 2011).

Yulafin yaygın olan hastalık ve zararlıları arasında yulaf taçlı pası, kara pas, rastık, külleme, yaprak lekesi, Arpa sarı cücelik virüsü, bakteriyel yanıklık, toprak kökenli virüsler ve nematodlar bulunmaktadir (Chong, 2003; Lin, 2012). Yulaf taçlı pas (Puccinia coronata f. sp. avenae) hastalığı, yulafın en zararlı ve önemli ekonomik kayıplara neden olan hastalığı olarak kabul edilmektedir (Chong vd., 2008; Paczos-Grzeda vd., 2018; Miller vd., 2018). Hastalık etmeni; obligat biyotrofik olan Pucciniomycetes sinıfin da bulunan tipik bir makrosiklik (Macrocyclic) ve heteroecious (iki konukçulu) fungustur (Nazareno vd., 2018; Miller vd., 2018). Yulaf taçlı pas hastalığ 1 etmeninin teliosporelarının uç kısımlarının mikroskop altındaki görüntüsü taç şekline benzetildiği için bu ismi almıştır (Şekil 
1). Etmen, çok kurak bölgeler hariç dünyanın her yerinde yetiştirilen kültür ve yabani yulaflarda hastalık meydana getirmekte ve yetişme sezonu boyunca hastalığın gelişmesi için uygun seyreden iklim koşullarında (15-25 ${ }^{\circ} \mathrm{C}$ sıcaklık, yüksek nem ve sık çiğ) önemli verim ve tane kalitesi kayıplarına sebep olmaktadır. Enfeksiyon için uygun şartlar oluştuğunda \%10'dan \%40'a kadar verim kayıplarının yanı sıra yatmaya, düşük saman verimi, zayıf tane dolumuna, tane kalitesinde ve hektolitre ağırlığında azalmaya, yeşil ot veriminde düşmeye neden olmaktadır (Holland ve Munkvold, 2001; Long vd., 2006; Nazareno vd., 2018; Anonim, 2020b).

Yulaf taçlı pas hastalığının tanımı ilk defa $1767^{\prime}$ 'de Tozzetti (1952) tarafindan yapılmış olup, bu zamana kadar farklı araştırıcılar tarafindan fizyolojik formlara (formae speciales) ve alt türlere ayrılmasını içeren birkaç alt bölüm farklı araştırıcılarca önerilmiştir (Simons, 1985; Nazareno vd., 2018). Puccinia coronata sensu lato'sı içindeki varyasyonları yansıtmak için, sınıflandırmaların çoğu spor morfolojisine, telial ve Aecial evresinin konukçularına dayanılarak yapılmıştır (Nazareno vd., 2018). Fakat bu tür adlandırmalar gerçek konukçu dizini ya da izolatlar arasındaki genetik farklılıkları yansitmada yetersiz kalabilmektedir. (Anikster vd., 2003; Nazareno vd., 2018). Bununla birlikte, bu adlandırmaların bazıları, Puccinia coronata örneğinde olduğu gibi büyük buğdaygil konukçularını belirtmek için kullanılmaktadır (Nazareno vd., 2018).

Ülkemizde yulaf taçlı pas hastalığı hakkında; Dumlupınar ve ark., (2016)'nın gen bankalarından ülkemize ait 375 köy çeşidini temin ederek, bunların genetik çeşitliliğini ve taçlı pas hastalığına reaksiyonlarını belirlemek için yapmış olduğu çalışmanın dışında kaynağa rastlanmamıştır. Tarım ve Orman Bakanlığı tarafından hazırlanan "Zirai Mücadele Teknik Talimatlar"1nda (Anonim, 2008) ve "Bitki Koruma Ürünleri Veri Tabanında" (Anonim, 2020i) yulaf taçlı pas hastalı̆̆ bilgilendirmeye rastlanmamıştır. $\mathrm{Bu}$ derleme ile yulafın en önemli ve tahripkâr hastalığ1 olarak kabul edilen yulaf taçlı pas hastalığının coğrafi dağılımı, ekonomik önemi, biyolojisi, belirtileri, zararı, konukçuları ve mücadelesi ile ilgili güncel bilgilerin derlenmesi amaçlanmış ve ülkemizde bu hastalığın kontrolüne ilişkin öneriler sunulmuştur.

\section{Coğrafi Dağılımı}

Yulaf taçlı pas hastalığg çok kurak bölgeler hariç yulaf yetiştiriciliğinin yapıldığ 1 dünyanın her yerinde kültür yulafları ve yabani yulaflarda hastalık meydana getirmekte ve yetişme sezonu boyunca hastalığın gelişmesi için uygun seyreden iklim koşullarında hassas çeşitlerde epidemi yaparak kantitatif ve kalitatif kayıplarına neden olmaktadır (Miller vd., 2018; Anonim, 2020b).

\section{Ekonomik Önemi}

Yulaf taçlı pas hastalığ yulafin en yaygın ve önemli kayıplara yol açan hastalığıdır (Omidvar vd., 2018; Anonim, 2020b). Dünyanın yulaf yetiştirilen bazı alanlarında özellikle hassas çeşitlerin ekili olduğu alanlarda epidemilere yol açtığına dair farklı raporlar bulunmaktadır. Etmenin ilk defa 1800'lü yılların sonunda yulaflarda değişen düzeylerde 
kayıplara neden olduğu bildirilmiş ve 1880 'ler de Avrupa'da, 1887'de Baltık devletlerinde (Danimarka, Estonya, Finlandiya, Almanya, Letonya, Litvanya, Polonya, Rusya ve İsveç) ve 1890'da Amerika Birleşik Devletleri'nde ilk defa raporlanmıştır (Nazareno vd., 2018). Günümüze kadar, yulaf taçlı pas hastalığı epidemileri yulaf üretimini etkilemeye devam ederek \%10 ile \%40 verim kaybına neden olabildiği bildirilmiştir. Yetişme sezonu boyunca hastalığın gelişmesi için uygun seyreden iklim koşullarında, özellikle hassas çeşitler üzerinde kayıplar en yüksek seviyelere ulaşabileceği rapor edilmiştir. Hastalık Güney Amerika (1916), Portekiz (1942), Avustralya (1952), İsrail (1953), Güneydoğu Avrupa'da (1959) ve Amerika Birleșik Devletleri’nde (1954) önemli verim ve kalite kayıplarına neden olmuştur. Brezilya ve Uruguay da 1990'dan beri neredeyse her yıl pas epidemisi gerçekleştirmiştir. Tunus (2010) ve Kanada (2008) da yulaf üretimi için ciddi tehdit oluşturmuştur (Nazareno vd., 2018).

İklim koşullarının enfeksiyon için uygun olmadığı veya inokulum baskısının fazla olmadığı yıllarda yulaf taçlı pas hastalığının meydana getirdiği kayılar \%5'e kadar düşebilmektedir (Nazareno vd., 2018).

Amerikan Tahıl Hastalıkları Laboratuvarı (Cereal Disease Laboratory (CDL))'nın değişik tarihlerde hazırlamış olduğu raporlara göre hastal1k epidemileri Amerika da 1981'den 2013’e kadar, 1991 ve 1993 de kuzey Dakota eyaletinde \%15, 1997'de Minnesota ve Louisiana eyaletlerinde \%20 verim kayıları ayrı tutulduğunda oldukça düşük seviye de seyretmiş ve meydana gelen ürün kayıpları \%10'dan daha az olmuştur. Hastalık 2014 y1lında epidemi yaparak ülkenin toplam yulaf üretiminin \%18.7'si oranında verim kaybına sebep olmuştur. Epidemiden dolayı özellikle Minnesota'da \%50, güney Dakota da $\% 35$ verim kaybı gerçekleşmiştir (Nazareno vd., 2018; Anonim, 2014).

\section{Tanımı ve Biyolojisi}

Puccinia coronata f. sp. avenae fungi alemi, Basidiomycota şubesi, Pucciniomycetes sinıfi, Pucciniales takımı, Pucciniaceae familyas1, Puccinia cinsinde yer alan obligat biyotrofik bir fungustur (Nazareno vd., 2018; Anonim, 2020b; Anonim, 2020c).

Puccinia coronata f. $\mathrm{sp}$. avenae heteroecious (farklı iki konukçulu) bir fungus olup yaşam döngüsü Şekil 2'de verilmiştir. Etmenin yaşam döngüsünde eşeyli ve eşeysiz üreme dönemlerinde basidiospor, pycniospore, aeciospore, urediniospore ve teliospore olarak adlandırılan beş farklı spor evresi bulunmaktadır (Anonim, 2020b; Anonim, 2020c). Yulaf taçlı pas hastalığı yulaf ile alternatif/ara konukçusunun (Rhamnus spp.) birlikte bulunduğu Ortadoğu, Avrupa ve Kuzey Amerika da etmen hem eşeyli hem de eşeysiz olarak üremekte iken; alternatif/ ara konukçusunun az olduğu veya bulunmadığ 1 Doğu Afrika, Güney Amerika, Avustralya ve Yeni Zelanda da sekonder enfeksiyonlarla eşeysiz üremektedir. Eşeyli ve eşeysiz üreme alternatif/ ara konukçuda meydana gelirken, eşeysiz üreme tamamen yulafta olmaktadır. Eşeysiz üreme urediniosporlar tarafından uygun iklim koşullarında iki haftada bir hızla tekrarlanabilen enfeksiyon ve sporülasyon döngülerini içermektedir. $\mathrm{Bu}$ aşamada Puccinia coronata f. sp. avenae dikaryotik olup, urediniosporlar içerisinde haploid iki çekirdek bulunmaktadır 
(Nazareno vd., 2018; Anonim, 2020b).

Urediniosporelar uygun şartlarda (15$25^{\circ} \mathrm{C}$ sıcaklık, yeterli nem ve kısa süreli 1şık) yaprağın alt ve üst yüzeyinde çimlenerek appressoria ve daha sonra mantarın stomaya nüfuz ederek yaprağın mezofil boşluğuna erişmesini sağlayan bir penetrasyon çivisi oluşturmaktadır. Penetrasyon çivisi aproseryumdan büyür ve konukçu yaprağına nüfuz ettikten sonra haustorial anne hücreler üretmek için hif uzatır. Haustorial ana hücresi konukçu mezofil hücrelerine temas ettiğinde bir haustorial aparatı oluşturur ve bir üredium üretmek için konukçu hücrelerden beslenmeye başlar. Ürediumlar hastalığın karakteristik belirtisini gösteren parlak turuncu-sarı dikdörtgen şeklinde püstüller olarak ortaya çıkar. Bu ürediumlardan 7-10 gün sonra başka yulafları enfekte edecek urediniosporlar üretilir. Yetişme sezonunun sonlarına doğru bitki yaşlanmaya başlayınca teliosporlar meydana gelir. $\mathrm{Bu}$ teliosporlar kalın koyu kahverenci hücre duvarlana sahip dikaryotik kışlama sporlarıdır. İlkbaharda mayoz bölünme geçirerek Rhamnus spp.'nin yapraklarını infekte edecek haploid basidiosporları oluştururlar. Yeni üretilen basidiosporlar, kromozomların rastgele dağılması ve genetik rekombinasyonun bir sonucu olarak, ebeveyn teliosporlardaki haploid çekirdeklerinden farklı genotiplere sahiptir. Basidiosporlar, alternatif/ara konukçuyu (Rhamnus spp.) enfekte etmek için birkaç yüz metre rüzgârla taşınabilirler. Basidiosporlar uygun çevresel koşullar altında bir alternatif/ ara konukçunun yaprağına ulaştı̆̆ında, çimlenir ve appressoria oluşturur. $\mathrm{Bu}$ appressoriumdan bir penetrasyon çivisi ile yüksek turgor basinc1 kullanarak alternatif/ara konukçunun kütiküla ve epidermisine nüfuz eder. Bir - iki hafta sonra, alternatif/ara konukçunun yaprağının üst yüzeyinde haploid miselyumdan Pycnia oluşur. Pycnia, yapraklarda, yaprak sapında, genç gövdelerde oluşabilir. Pycniaların içindeki sporoforların uçlarında üretilen pycniosporlar küçük, yuvarlak, turuncu-sarıdır ve yapraktan hafifçe yukarıya doğru kabarıktır. Erkek gamet olarak kabul edilen pycniosporlar, dişi alıcı yapılar olarak işlev gören esnek hifsel yapıya girebilir. Pycniosporlar, aynı Pycniadan oluşan esnek hifsel yapılarla çiftleşemezler. Herbir pikniyum ya (+) çiftleşme tipi veya (-) eşleşme tipidir. Başarılı bir şekilde çiftleşmek için, karşı eşleşme tipinin uyumlu esnek hifsel yapısına aktarılır (Nazareno vd., 2018; Lin, 2012; Anonim, 2020b; Anonim, 2020c).

Pycniadan sonra alternatif/ara konukçunun yapraklarının alt yüzeyinde Aecia oluşur. Aeciaların esnek hifsel yapılarının içerisindekarşıeşleşmetipininuyumluesnekhifsel yapısına aktarılan pycniospore çekirdeklerinin birleşmesinden oluşan dikaryotik (iki karşı1t çekirdeğe sahip) Aeciosporlar vardır. Böylelikle yaprağın alt yüzeyinde oluşan Aecidiumlar çok sayıda farklı Aeciospore genotipini içerirler. Aecidiumlar sarı turuncu renkli, yuvarlak, küçük fincan kümeleri görünümlü uzun zincirler şeklindedir. Aeciosporlar rüzgârla taşınır ve uzun mesafeler kat edebilirler. Aeciosporlar alternatif/ ara konukçudan salınır ve ana konukçularını enfekte ederler. Aeciosporlar konukçu bitkiye stomalardan girer ve konukçu bitkinin içerisinde stomatal bir kese şeklinde Appressoria oluşturur. Konukçu dokunun içerisinde dikaryotik aeciosporun gelişmesinden bir dikaryoktik miselyum büyür. Daha sonra Uredium gelişir ve 
dikaryotik urediniosporun birkaç generasyonunu üretir. Urediumlar ana konukçunun (Avena spp.) üzerinde yaprakta, nadiren yaprak kınında ve başakta bulunmaktadır. Parlak turuncusarı urediniosporlar yuvarlak veya dikdörtgen şeklinde püstüller halinde üretilmektedir. Urediumların (püstüllerin) uzunluğu $5 \mathrm{~mm}$ ye ulaşabilmektedir. Dayanıklı yulaf çeşitlerindeki semptomlar küçük açık renkli lekelerden, klorotik veya nekrotik alanlarla çevrili küçük veya orta boy püstüllere kadar değişmektedir. Urediniosporlar, diğer yulaf (Avena spp.) bitkilerini enfekte etmek için rüzgârla uzun mesafelere (150 km'ye kadar) taşınarak büyük verim kaybı ve düşük tane kalitesi ne neden olmaktadır (Lin, 2012; Nazareno vd., 2018; Anonim, 2020b).

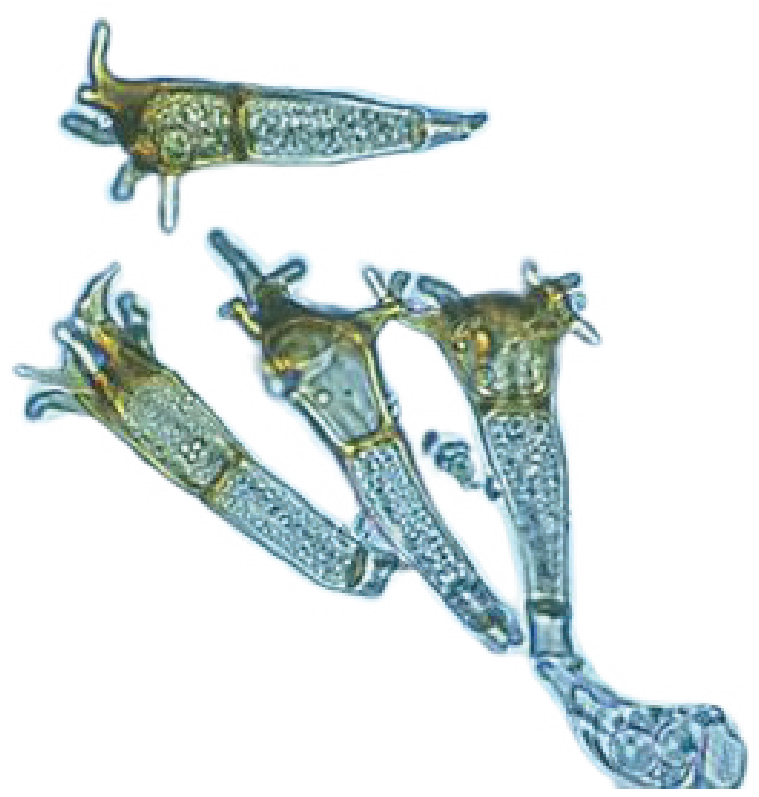

Şekil 1. Teliosporların Mikroskop altındaki görüntüsü (Anonim, 20201)

Yulaf taçlı pas hastalığı çiğ oluşumu için yeterince nem olan 1lik geceler $\left(15-20^{\circ} \mathrm{C}\right.$ sıcaklık) ve 1lık güneşli günler de $\left(20-25^{\circ} \mathrm{C}\right.$ sıcaklık) en iyi gelişmektedir. Gün ortasındaki rüzgâr sporların çevreye yayılması ve yeni yulaf bitkilerini enfekte etmek için önemlidir. Urediniosporlar ve aeciosporların rüzgârla uzun mesafelere taşınıp yulaf bitkilerini enfekte ederek epidemi oluşturmalarından ziyade alternatif/ara konukçunun (Rhamnus spp.) olduğu yerlerde meydana getirdiği epidemileri çok daha önemlidir. Çünkü etmenin her iki konukçusunun da olduğu bölgelerde hastalığın yeni ırklarının ortaya çıkma olasılığı eşeyli üremesinden dolayı çok daha muhtemeldir. Alternatif/ara konukçunun (Rhamnus spp.) olduğu yerlerde etmen teliospore olarak enfekte olmuş yulaf (Avena spp.) bitkilerinde kışı geçirir. Baharın teliosporlar çimlenerek mayoz bölünmeyle basidiosporları oluşturur. Basidiosporlar çevredeki Rhamnus spp.'ni enfekte eder ve burada oluşan aeciosporlar yulafları (Avena spp.) enfekte eder. Aeciosporlar 2,5 km'ye kadar taşına bilmektedir. Enfekte olmuş yulaflarda (Avena spp.) oluşan urediniosporlar sekonder enfeksiyonları meydana getirmektedir. Her iki enfeksiyon deseni de temel bulaşma kaynağ bakımından önemlidir (Lin, 2012; Nazareno vd., 2018; Anonim, 2020b).

\section{Belirtileri ve Zararı}

Hastalığın tarladaki belirtileri; konukçu yaprağının epidermisi yırtıldıktan sonra ürediniospor kitlesini içeren, açık portakal sarıs1 püstüllerle ortaya çıkmaktadır. Püstüller (Uredium) oval veya dikdörtgen şekilli olup, 


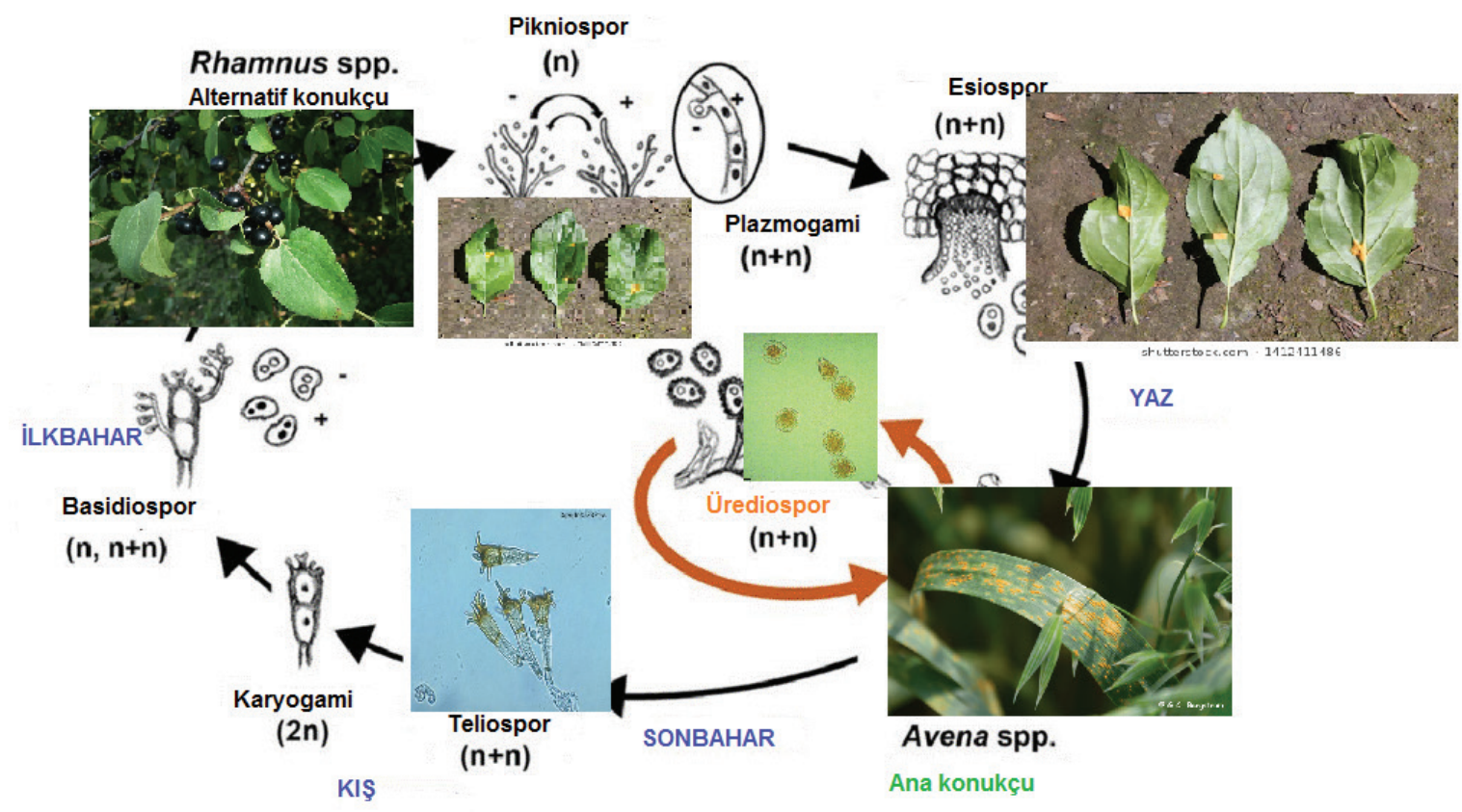

Şekil 2. Yulaf taçlı pas hastalığının (Puccinia coronata f. sp. avenae) yaşam çemberi (Nazareno vd., (2018)'den uyarlanmıştır)

boyları 5 mm'yi bulabilmektedir. Bu lezyonlar ana konukçunun üzerinde (Avena spp.) yaprakta (yaprağın her iki yüzeyinde), nadiren yaprak kınında ve başakta olabileceği gibi, şiddetli epidemilerde bitkinin tüm yeşil aksamında görülebilmektedir (Şekil 3) (Anonim, 2020b; Anonim, 2020d; Nazareno vd., 2018). Hastalik gelişimi için uygun olmayan dönemde, teliosporların oluşmaya başlaması ile püstüllerin rengi siyah renge dönüşmekte ve enfekte bitkiler hasat olgunluğuna ulaştığı zaman ürediniospor üretimi tamamen son bulmaktadır (Şekil 2). Teliosporlar kalın koyu kahverengi hücre duvarlarına sahip, dikaryotik kışlama sporlarıdır. Teliosporlar ilkbaharda mayoz bölünme geçirerek alternatif/ara konukçunun (Rhamnus spp.) yapraklarını enfekte edecek haploid basidiosporları oluşturmaktadır. Basidiosporlar uygun çevresel koşullar altında alternatif/ara konukçunun yaprağına ulaştığında, çimlenmekte ve bir iki hafta sonra, Pycniaları oluşturmaktadır. Pycnia, yapraklarda, yaprak sapında, genç gövdelerde oluşabilmekte ve içindeki sporoforların uçlarında üretilen küçük, yuvarlak, turuncu-sarı ve yapraktan hafifçe yukarıya doğru kabarmış şekilde olan piknosporları içermektedir (Şekil 4).

Pycniadan sonra alternatif/ara konukçunun yapraklarının alt yüzeyinde aecia oluşur. Aeciaların esnek hifalarının içerisinde aeciosporlar vardır. Esiumlar sarı-turuncu renkli, yuvarlak, küçük fincan kümeleri görünümlü uzun zincirler şeklindedir (Şekil 4). Aeciosporelar rüzgârla ana konukçu bitkilerin yaprakları 

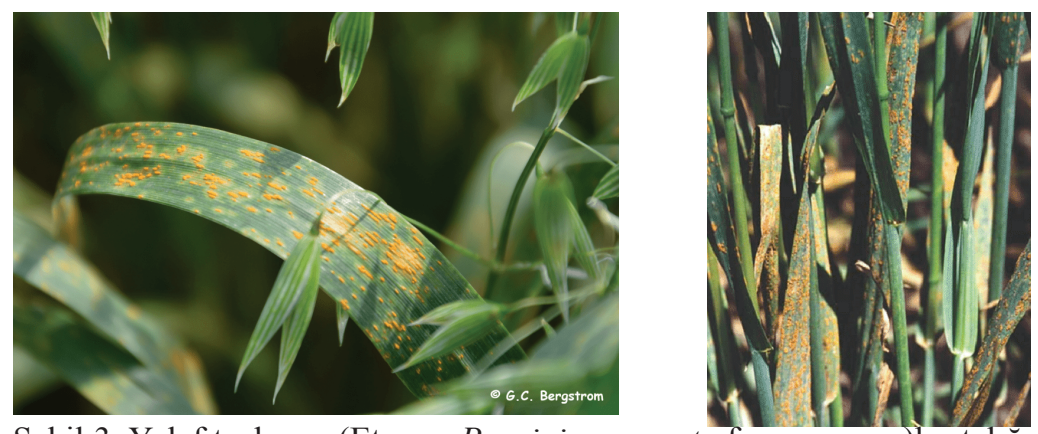

Şekil 3. Yulaf taçlı pas (Etmen: Puccinia coronata f. sp. avenae) hastalığın yulaf yaprağı üzerinde ki belirtileri (Nazareno vd..2018: Fulcher vd...2020).
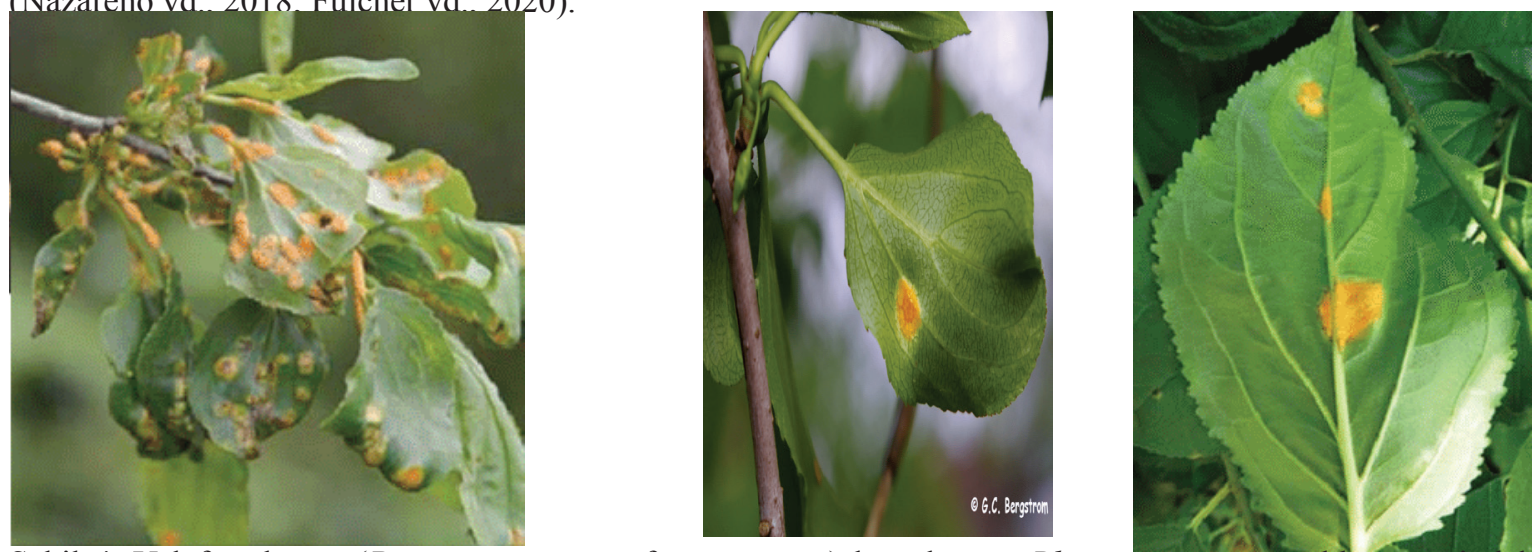

Şekil 4. Yulaf taçlı pas (Puccinia coronata f. sp. avenae) hastalığının Rhamnus spp. yaprakları üzerindeki belirtileri (Nazareno vd., 2018; Fulcher vd., 2020)

üzerine taşınarak uygun sicaklık ve nem koşullarında çimlenip, urediniosporları meydana getirirler (Şekil 5). Bu sporlar da konukçu bitkileri tekrar uygun iklim koşullarında enfekte

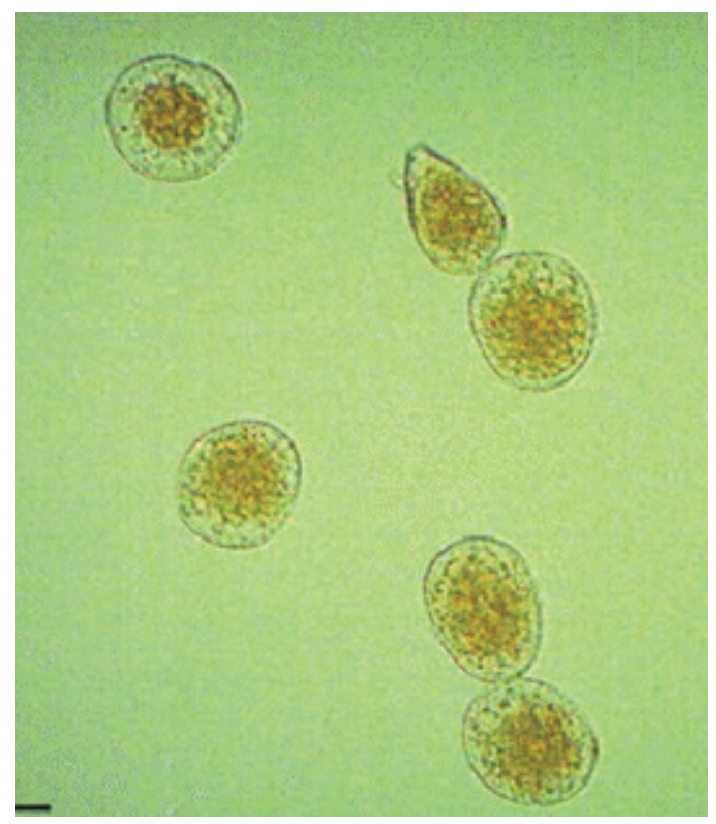

Şekil 5. Ürediniosporların Mikroskop altındaki görüntüsü (Nazareno vd., 2018) 
ederler. İklim koşullarının uygun olmadığı durumlarda konukçu bitkilerde teliosporlar oluşur ve döngü tamamlanır. (Simons, 1985; Lin, 2012; Nazareno vd., 2018; Anonim, 2020b; Anonim, 2020d).

Primerenfeksiyonlarurediniosporlarveya aeciosporlar tarafindan gerçekleştirilmektedir. Kışlık yulaf yetiştirilen subtropikal ve 1lıman iklimbölgelerinde, yazaylarında canlı kalankendi gelen yulaf bitkilerinde üretilen urediniosporlar genellikle sonbaharda ekilen bitkilerin birincil enfeksiyonlarından sorumludur. Alternatif/ara konukçunun (Rhamnus spp.) olduğu Avrupa ve Kuzey Amerika'da Rhamnus spp. yulaf için önemli bir inokulum kaynağıdır. Çünkü eşeyli üreme ile patojen popülasyonunda gözlenen varyasyona rekombinasyon yoluyla katkıda bulunmaktadır (Anonim, 2020b; Nazareno vd., 2018; Simons, 1985).

Urediniosporlar ve aeciosporlar rüzgar tarafından uzun mesafelere taşınmakta ve stoma gibi doğal açıklıklar vasıtasıyla enfeksiyonu gerçekleştirmektedirler. Sporların çimlenebilmesi için yaprak yüzeyinin rslak ve sicaklığın $\quad 10-25 \quad{ }^{\circ} \mathrm{C}$ arasında olması gerekmektedir. Enfeksiyon $30^{\circ} \mathrm{C}$ 'nin üzerindeki sicaklıklarda gerçekleşmemektedir (Simons, 1985; Anonim, 2020b; Anonim, 2020d).

Yulaf taçlı pas hastalığı üründe değişen düzeylerde verim ve tane kalitesi kayıplarına neden olmaktadır. Yetişme sezonu boyunca hastalığın gelişmesi için uygun seyreden iklim koşullarındaki şiddetli enfeksiyonlarda saman veriminde düşme, yatma, hatta soğuk zararı görülebilmektedir. Ayrıca hastalık şiddeti ile verim, tane ağırlığı, bin tane ağırlığı ve ürünün tane dolumu ile negatif korelasyon bulunmaktadır (Lin, 2012).

\section{Konukçuları}

Puccinia coronata sensu lato's1 290 buğdaygil türünü enfekte edebilmektedir. Ancak yaygin olarak yulaf türleri (Avena spp.) ana konukçularıdır. Bu konukçulara ek olarak çayır çam otlarında, çok yıllık İngiliz çimlerinde, yumaklarda, arpa ve çavdarda hastalık meydana getirebilmektedir. Alternatif/ara konukçusu olan adi cehrinin (Rhamnus spp.), $R$. cathartica, $R$. alnifolia, $R$. lycioides ve $R$. frangula türlerinde de konukçu olduğu bildirilmiştir (Simons, 1985; Lin, 2012; Nazareno vd., 2018; Anonim, 2020b).

\section{Mücadelesi}

Yulaf taçlı pas hastalığının kontrolünde erken ekim, sık ekimden kaçınma (uygun ekim normu kullanmak), aşırı azotlu gübreleme yapılmaması, alternatif konukçuların yok edilmesi, dayanıklı çeşit kullanılması ve fungisit uygulamaları önerilmektedir (Simons, 1985; Chong, 2008; Lin, 2012; Nazareno vd., 2018).

Hastalığın mücadelesinde öne çıkan kontrol yöntemi dayanıklı çeşit kullanımıdır. Dayanıklı çeşit kullanımı, çevreye saygıll, sürdürülebilir ve etkinliği yüksek bir çözümdür. Hastalığa dayanıklı çeşitlerin temelini, ırka özgü dayanıklılık gösteren çeşit 1slahı oluşturmakta ve patojendeki aynı kökenli avirulens (Avr) faktörlerinin tanınmasına aracılık eden dominant 
dayanıklılık $(R)$ genlerinin uyuşmasından meydana gelmektedir (Miller vd., 2018). Yani, konukçuda dayanıklı $(R)$ ve patojende avirulens (Avr) dominanttır. Konukçunun dayanıklılığ1 için sadece tek bir uyumsuz gen etkileşimi gereklidir (Lin, 2012). Bugüne kadar, yulafta (Avena spp.) 100'den fazla dayanıklilık geni (Pc) belirlenmiștir (Nazareno vd., 2018; Paczos-Grzeda vd., 2018). Yürütülen birçok 1slah programında dayanıklılık kaynağı olarak hekzaploid $A$. sativa L.'dan (Pc3c, Pc4c, Pc6c, Pc6d, Pc9, Pc13, Pc22, Pc95, Pc96), A. byzantina'dan (Pc1-Pc8, Pc9c, Pc10-Pc12, Pc14, Pc21), A. sterilis'den (Pc38, Pc39, Pc48, Pc50, Pc58, Pc59, Pc60, Pc61 ve Pc68), diploid A. strigosa (AsAs)'dan (Pc15, Pc16, Pc17, Pc19, Pc23, Pc30, Pc37, Pc81, Pc82, Pc83, Pc84, Pc85, Рc86, Рc87, Рc88, Рc89, Рc90, Pc94) genleri kullanılmaktadır (Paczos-Grzeda vd., 2018). Ancak etmenin eşeyli ve eşeysiz üreme dönemini kapsayan yaşam döngüsünden dolayı virülenslik ve agresiflik bakımından farklı olan yeni pas patotipleri/1rkları ortaya çıkmaktadır. Etmenin yaşam döngüsündeki eşeyli üreme kısmının (alternatif konukçunun yer aldığı ve mayotik rekombinasyon olaylarının gerçekleştiği) olmadığı durumda, mutasyon ve somatik rekombinasyonla yeni patotipler/ 1rklar oluşmaktadır. Böylelikle patojenin sürekli evrimi nedeniyle, yulaf taçlı pas hastalığına karşı mevcut dayanıklılık kaynakları etkinliğini hizla kaybetmektedir (Paczos-Grzedan vd., 2018). Buna karş1 üreticilere pas epidemisinden daha az etkilenmeleri için bölgenin iklim şartlarını, etmenin patotip/ırklarını, alternatif/ ara konukçu varlığını göz önünde bulundurarak aynı yetiştiricilik alanına iki veya üç farklı yulaf çeşidi ile ekim yapmaları tavsiye edilebilir (Anonim, 2020e; Anonim, 2020f).

Yulaf taçlı pas hastalığının kontrolünde öne çıkan bir diğer kontrol yöntemi fungisit uygulamalarıdır. Fungisit uygulamalarına, ürünün ekonomik getirisi ve ilacın uygulama maliyetleri değerlendirilip maliyet-fayda analizi yapılarak karar verilmelidir. Hastalığın gelişmesi için uygun iklim koşullarının varlığı, ekilen çeşidin bölgede yaygın olan pas patotipi/ ırkına karşı hassasiyeti, hastalığın gelişimi izlenerek bitkinin bayrak yaprağ1 enfekte olmadan önce fungisit uygulanmalıdır. Orta dayanıklı bir çeşit erken ekilerek ve uygun fungisit uygulaması ile verim artışı sağlanma olasılığ1 düşüktür (May vd., 2014). Fungisit seçimi hasattan önce bekleme sürelerine dikkat edilerek yapılmalıdır. Yulaf taçlı pası (Puccinia coronata f. sp. avenae)'nın yüksek yeniırk/ patotip kapasitesi (virülenslik ve agrasiflik bakımından farklı olan yeni pas patotiplerinin ortaya çıkması) ve yulafta fungisitlerin artan kullanımı, bu patojende fungisit hassasiyeti olasılığını artırmaktadır (Nazareno vd., 2018). Bu nedenle ilaçlamalarda etki mekanizması farklı fungusitler kombineli olarak kullanılmalıdır. Yulaf taçlı pas hastalığının mücadelesinde pyraclostrobin, azoxystrobin, trifloxystrobin, propiconazole +tryfloxystrobin, propiconazole, prothioconazole, propiconazole+azoxystrobin ve metaconazole+pyraclostrobin etken maddeli ilaçlar önerilmektedir (Nazareno vd., 2018; Anonim, 2020g; Anonim, 2020h). Hastalık için önerilen etken maddelerin bazıları geniş kapsamda pas türlerine (Puccinia spp.) karş1 ülkemizde ruhsatlandırılmıştır. 


\section{Sonuç}

Yulaf taçlı pas hastalığı, yulafin önemli ve değişen düzeylerde ekonomik kayıplara neden olan hastalığı olarak kabul edilmektedir (Chong vd., 2008; Paczos-Grzeda vd., 2018; Miller vd., 2018). Etmen obligat, biyotrofik, makrosiklik ve heteroecious (iki konukçulu) fungustur (Nazareno vd., 2018; Miller vd., 2018). Etmenin yaşam döngüsünde; eşeyli ve eşeysiz üremesinin olduğu basidiospor, pycniospore, aeciospore, urediniospore ve teliospore'dan oluşan beş farklı spor evresi bulunmaktadir (Anonim, 2020b; Anonim, 2020c). Puccinia coronata f. sp. avenae yulaf ile alternatif/ara konukçusunun (Rhamnus spp.) birlikte bulunduğu Ortadoğu, Avrupa ve Kuzey Amerika da, hem eşeyli hem de eşeysiz olarak üremekte iken; alternatif/ara konukçusunun az olduğu veya bulunmadığı Doğu Afrika, Güney Amerika, Avustralya ve Yeni Zelanda da eşeysiz üremektedir. Eşeyli üreme hem yulafta hem de alternatif/ara konukçuda meydana gelirken, eşeysiz üreme tamamen yulafta olmaktadır. Etmenin yaşam döngüsünden dolayı virülenslik ve agresiflik özelliği yönüyle farklı olan yeni patotipleri/ırkları ortaya çıkmaktadır. Patojenin sürekli evrimi nedeniyle, mevcut dayanıklılık genleri etkinliğini hızla kaybetmektedir (PaczosGrzeda vd., 2018).

Yulaf taçlı pas hastalığı çok kurak bölgeler hariç dünyanın her yerinde başta yulaf olmak üzere yaklaşık 290 konukçu da hastalık meydana getirebilmekte ve yetiştirme sezonu boyunca hastalık gelişimi için uygun iklim şartlarında değişen düzeylerde verim ve kalite kayıplarına neden olmaktadır (Holland ve Munkvold, 2001; Long vd., 2006; Nazareno vd.,
2018; Anonim, 2020b;). Hastalığın kontrolünde erken ekim, sık ekimden kaçınma (uygun ekim normu kullanmak), aşırı azotlu gübreleme yapılmaması, alternatif konukçuların yok edilmesi, dayanıklı çeşit kullanılması ve fungisit uygulamaları önerilmektedir (Simons, 1985; Chong vd., 2008; Lin, 2012; Nazareno vd., 2018).

Yulaf taçlı pas hastalığı (Puccinia coronata f. sp. avenae) ile ilgili ülkemizde yeterli düzeyde çalışma yapılmamıştır. $\mathrm{Bu}$ nedenle öncelikli olarak;

- Her yıl sürveylerle hastalığın bulunma oranı ve şiddeti ortaya konmalı,

- Ülke ve bölgesel düzeyde etmenin hangi hastalık ırklarının olduğu tespit edilmeli,

- Ülkemizde şu an için tescil edilmiş 17 adet ve üretim izini bulunan 5 adet yulaf çeşidinin (Anonim, 2020k), Yulaf taçlı pas hastalığına karşı reaksiyonu belirlenerek, hangi dayanıklılık genlerini içerdiği belirlenmeli,

- Farklı dayanıklılık genleri tespit edilen hekzaploid $A$. serilis'in orijini ülkemizdir. Ülkemizdeki $A$. serilis türleri toplanıp karakterize edilerek, hangi dayanıklılık gen/ genlerini içerdiği veya belirlenmemiş gen/ genlerinin varlığı araştırılıp, hastalığa karşı etkin dayanıklılık geni taşıyanların 1slah programlarına entegrasyonun sağlanması,

- Islah programlarında etmenin patotip/ ırklarına karşı fenotipe dayalı seleksiyonun yanı sıra, moleküler 1slah yaklaşımlarının da kullanarak yapılması,

gibi çalışmaların yapılması önerilmektedir. 


\section{KAYNAKLAR}

Anikster Y., Eilam T., Manisterski J. and Leonard KJ., 2003. Self-fertility and other distinguishing characteristics of a new morphotype of Puccinia coronata pathogenic on smooth brome grass. Mycologia 95(1), 87-97.

Anonim, 2008. Zirai Mücadele Teknik Talimatları, Tarım Gıda ve Hayvancılık, Cilt 1.

Anonim, 2014. (https://www.ars.usda.gov/ midwest-area/stpaul/cereal-disease-lab/ docs/small-grain-losses-due-to-rust/smallgrain-losses-due-to rust/) (Erişim tarihi $: 14.02 .2020)$

Anonim, 2020a. (https://www.fas.usda.gov/data/ world-agricultural-production) (Erişim tarihi: 14.02.2020)

Anonim, 2020b. (https://www.ars.usda.gov/ midwest-area/stpaul/cereal-disease-lab/ docs/cereal-rusts/oat-crown-rust/) (Erişim tarihi: 13.02.2020)

Anonim, 2020c. (https://en.wikipedia.org/ wiki/Puccinia_coronata)

(Erişim tarihi:14.02.2020)

Anonim, 2020d. (http://www.fao.org/3/y5765e/ y5765e0g.htm) (Erişim tarihi:17.02.2020) Anonim, 2020e. (https://www.topcropmanager. com/controlling-oat-crown-rust-19016/) (Erişim tarihi: 18.02.2020)

Anonim, 2020f. (https://www.saskatchewan. $\mathrm{ca} /$ business/agriculture-natural resourcesand-industry/agribusiness-farmers-andranchers/crops-and irrigation/disease/ crown-rust-of-oat) (Erişim tarihi: 18.02.2020)
Anonim, 2020g. (http://nwdistrict.ifas.ufl.edu/ phag/2013/12/13/crown-rust-outbreakin-north-florida-oats/ ) (Erişim tarihi: 19.02.2020)

Anonim, 2020h. (https://agcrops.osu.edu/ newsletter/corn-newsletter/2019-29/ oat-crown-rust-forages (Erişim tarihi: 19.02.2020)

Anonim, 2020i. ( https://bku.tarim.gov.tr) (Erişim Tarihi: 19.02.2020)

Anonim, 20201. (https://alchetron.com/Pucciniacoronata) (Erişim tarihi:19.02.2020)

Anonim, 2020k. (https://www.tarimorman. gov.tr/BUGEM/TTSM/Menu/30/KayitListeleri) (Erişim Tarihi: 18.02.2020)

Carson ML., 2009. Broad-spectrum resistance to crown rust, Puccinia coronata f. sp. avenae, in accessions of the tetraploid slender oat, Avena barbata. Plant Disease 93:363-366.

Chong J., 2003. Diseases of oat. Pages 74-88 in K. L. Bailey, B. D. Gossen, R. K. Gugel, and R. A. A. Morrall, eds. Diseases of field crops in Canada. University Extension Press, University of Saskatchewan, Saskatoon, SK.

Chong J., Gruenke J., Dueck R., Mayert W. and Woods, S., 2008. Virulence of oat crown rust [Puccinia coronata f. sp. avenae] in Canada during 2002-2006. Canadian Journal of Plant Pathology 30:115-123.

Dumlupınar Z., Dokuyucu T., Maral H., Kara R., Akkaya A., 2012. Evaluation of Turkish Oat Landraces Based on Morphological and Phenological Traits. ZemdirbysteAgriculture, 99(2), 149-158. 
Dumlupınar Z., Jellen EN., Bonman JM., Eric W., Jackson EW., 2016. Genetic diversity and crown rust resistance of oat landraces from various locations throughout Turkey. Turk J. Agric For (2016) 40: 262-268, TUBİTAK. doi:10.3906/tar-1509-43.

Fulcher MR., Benscher D., Sorrells ME., and Bergstrom GC., 2020. Preserving spring oat yields in New York through varietal resistance to crown rust. Plant Health Progress, Published On-line 21 January2020 (https://apsjournals.apsnet. org/doi/10.1094/PHP-05-19-0037-RS).

Holland J. and Munkvold G., 2001. Genetic relationships of crown rust resistance, grain yield, test weight, and seed weight in oat. Crop Science 41:1041-1050.

Lin Y., 2012. Genetic Analysis of Puccinia coronata Corda f. sp. avenae Resistance in Oat (Avena sativa L.). University of Saskatchewan, Department of Plant Sciences, Degree of Master, Canada. 89s.

Long J., Holland J., Munkvold G. and Jannink J., 2006. Responses to selection for partial resistance to crown rust in oat. Crop Science 46:1260-1265.

Loskutov IG. and Rines HW., 2011. Avena. In: Wild Crop Relatives: Genomic \& Breeding Resources, vol. 1. Cereals. (Eds.) Kole, C. Springer, ISBN 978-3-642-14227-7, New York, NY. pp. 109-185, DOI 10.1007/9783-642-14228-4.

Ludwig DS., Pereira MA., Kroenke CH., Hilner JE., Van Horn I., Slattery ML., and Jacobs DR., 1999. Dietary fiber, weight gain and cardiovascular disease risk factors in young adults. JAMA: 282:1539-1546.

Maki KC., Galant R., Samuel P., Tesser J., Witchger MS., Ribaya-Mercado JD., Blumberg JB. and Geohas J., 2007. Effects of consuming foods containing oat B-glucan on blood pressure, carbohydrate metabolism and biomarkers of oxidative stress in men and women with elevated blood pressure. European Journal of Clinical Nutrition 61:786-795.

May WE., Ames N., Irvine RB., Kutcher HR., Lafond GP. and Shirtliffe SJ., 2014. Are fungicide applications to control crown rust of oat beneficial? Canadian Journal of Plant Science, 2014, 94(5): 911922, https://doi.org/10.4141/cjps2013333.

Miller ME., Zhang Y., Omidvar V., Sperschneider J., Schwessinger B., Raley C., Palmer JM., Garnica D., Upadhyaya N., Rathjen J., Taylor JM., Park RF., Dodds PN., Hirsch CD., Kianian SF., Figueroa M., 2018. De novo assembly and phasing of dikaryotic genomes from two isolates of Puccinia coronata f. sp. avenae, the causal agent of oat crown rust. mBio 9:e01650-17. https:// doi.org/10.1128/mBio.01650-17.

Nazareno ES, Li F, Smith M, Park RF, Kianian SF, Figueroa M., 2018. Puccinia coronata f. sp. avenae: a threat to global oat production. Mol Plant Pathol. 19(5):10471060. doi: 10.1111/mpp.12608.

Omidvar V, Dugyala S, Li F, Rottschaefer SM, Miller ME, Ayliffe M, Moscou MJ, Kianian SF, Figueroa M., 2018. Detection of race-specific resistance against Puccinia coronata f. sp. 
avenae in Brachypodium species.

Phytopathology. 2018 Dec;108(12):1443-

1454. doi: 10.1094/PHYTO-03-18-

0084-R. Epub 2018 Oct 31.

Paczos-Grzeda E., Sowa S., Koroluk A. And

Langdon T., 2018. Characteristics of resistance to Puccinia coronata f. sp. avenae in Avena fatua L., Plant Disease 2018 102:12, 2616-2624 https://doi. org/10.1094/PDIS-03-18-0528-RE

Simons, M.D., 1985. Crown rust. In The Cereal Rusts Vol. II. (Roelfs, A. and Bushnell, W., eds), pp. 131-172. Orlando, Florida: Academic Press, Inc.

Strychar R., 2011. World Oat Production, Trade, and Usage.Oats Chemistry And Technology. Chapter 1. International Standard Book Number: 978-1-89112764-9.

Tozzetti, G., 1952. True nature, causes and sad effects of the rust, the bunt, the smut, and other maladies of wheat, and of oats in the field (L. R. Tehon, transl.). In: Phytopathol, Classic, No. 9. American Phytopathological Society, Washington, DC (originally published, 1767). 